\title{
ASSESS THE PREVALENCE OF PREMENSTRUAL SYNDROME AMONG ADOLESCENT GIRLS AT SRM COLLEGE OF NURSING, SRM UNIVERSITY, KATTANKULATHUR
}

\author{
ABIRAMI P, AMBIKA S \\ Department of Nursing, SRM College of Nursing, SRM University, Kattankulathur, Chennai, Tamil Nadu, India. \\ Email: abiramikarnamurthy@gmail.com
}

Received: 08 June 2016, Revised and Accepted: 02 February 2017

\section{ABSTRACT}

Objective: The aim of this study was to determine the prevalence of premenstrual syndrome (PMS) among adolescent girls and to associate the PMS with demographic variables.

Methods: Quantitative approach and non-experimental descriptive research design was used. The data collection included three parts. Part A: Demographic variables, Part B: Clinical variables, and Part C: A structured questionnaire to assess the prevalence of PMS among adolescent girls. A total of 100 students who fulfilled the inclusion criteria were chosen as samples using non-probability convenient sampling technique. The study was conducted at SRM College of Nursing, SRM University, Kattankulathur.

Results: The data were analyzed and interpreted based on the objectives using descriptive and inferential statistics. The study concluded that 26 (26\%) of adolescent girls have mild level of PMS; 55 (55\%) have moderate level of PMS; and 19 (19\%) have severe level of PMS and there is no association between the "demographic variables" and the "levels of PMS."

Conclusion: PMS is an issue that every girl and woman has to deal with in her life. There is a lack of information on the process of menstruation and the physical and psychological changes associated with this and proper requirements for managing PMS. The current study proved that most of the adolescent girls were suffering from PMSs

Keywords: Premenstrual syndrome, Physical, Cognitive-affective and behavioral symptoms, Menstruation.

(C) 2017 The Authors. Published by Innovare Academic Sciences Pvt Ltd. This is an open access article under the CC BY license (http://creativecommons. org/licenses/by/4. 0/) DOI: http://dx.doi.org/10.22159/ajpcr.2017.v10i5.13332

\section{INTRODUCTION}

Menstruation (a period) is a major stage of puberty in girls; it is one of the many physical signs that a girl is turning into a woman. The start of periods is known as menarche. Menstruation is also called menstrual bleeding, menses, catamenia, or a period. Although, every woman has an individual cycle of menstruation. The length of a woman's menstrual cycle will typically vary, with some shorter cycles and some longer cycles. A woman who experiences variations of $<8$ days between her longest cycles and shortest cycles is considered to have a regular menstrual cycle.

Menstruation is a normal physiological impact in each girl's life. Menstruation is a monthly uterine bleeding for 3-5 days after every 28 days from puberty till menopause. A change in mood, behavior, appearance of some abnormal vague symptoms is often noticed in the second half of the cycle. However, if the symptoms are severe enough to disturb lifecycle of women or require medical help, called premenstrual syndrome (PMS).

Natu says symptoms which occur during 1 week before menstruation is collectively known as PMS [1].

PMS is used to describe physical, cognitive-affective, and behavioral symptoms that occur cyclically during the luteal phase of the menstrual cycle and resolve quickly at or within a few days of the onset of menstruation. The American College of Obstetrics and Gynecology published the diagnostic criteria for PMS. It was considered if at least one of the 6 affective and one of the 4 somatic symptoms were reported 5 days before the onset of menses in the three prior menstrual cycles and ceased within 4 days of onset of menses. There are numerous symptoms that may occur, but the typical ones include somatic symptoms such as bland pain, pelvic pain, headache, skin disorders, and changes in bowel habits and the psychosocial symptoms such as irritability, aggressiveness, depression, anxiety, inability to concentrate, hypersomnia or insomnia, change in appetite, specific food craving, change in libido, and poor coordination [2]

Richarson reports that PMS can be characterized as a group of psychological and somatic symptoms that are limited to the week preceding menstruation and relieved by the onset of menses [3]. Most women experience some form of PMSs whether mild or severe at sometime in their life. Bakhshani reports a study related to prevalence and severity of premenstrual symptoms among Iranian Female University students. The high frequency of premenstrual symptoms and significant prevalence of PMS was found in our study sample. Preventive and treatment strategies for PMS are highly recommended (JPMA 59:205;2009) [4].

Al-Batanony conducted a study prevalence of PMS and its impact on quality of life among university medical students, AlQassium University, KSA. This study showed that the burden of PMS/premenstrual dysphoric disorder (PMDD) on health-related quality of life was on mental and emotional health-related quality of life domains beside on physical health-related quality of life domains as the students with PMS reported a poorer health-related quality of life as measured by SF-36 than those without PMS. PMS/PMDD is prevalent, yet undertreated, disorder among medical students in KSA, which adversely affected their quality of life [5].

Kaur conducted a study to assess the PMS and coping behavior among nursing students, Nine, Pgimer, Chandigarh. A descriptive study was conducted among 248 nursing students from all classes were chosen 
for collection of data. The questionnaire part one is an assessment of PMS and part two is for checklist on coping behavior. The most commonly (79.43\%) of 248 students having were a lower abdominal pain. $(66.12 \%)$ having backache and $(52.01 \%)$ having low efficiency of work performance. The majority of students were using healthy coping strategies. (89.11\%) do not blame themselves for this problem, (75.40\%) accept it as nothing can be done 181 (98.11\%) take hot or cold drinks [6].

Menstruation does not stop just because there is an emergency. While $80 \%$ of menstruating women have experienced at least one symptom that could be attributed to PMS, estimates of prevalence range from as low as $3 \%$ to as high as $30 \%$. The topic holds a paramount importance in the life cycle of a woman, the time of acquiring the age of adolescence. The knowledge level of a young girl at the age of 8-10 years is very meager to accept the myths and facts of the menstrual cycle and its associated problems [7]. There needs to be awareness in the mind of all the girls regarding the process and complications on the topic. Hence, the investigator wants to assess the prevalence and then to start with the awareness program on PMS.

The aim of this study was to determine the prevalence of PMS among adolescent girls and to associate the PMS with demographic variables.

\section{METHODS}

Quantitative approach and non-experimental descriptive research design was used. 100 adolescent girls who fulfilled the inclusion criteria were selected as samples using non-probability convenient sampling technique. The study was conducted at SRM College of Nursing, SRM University, Kattankulathur. The data collection included three parts. Part A was demographic variables, Part B was clinical variables, and Part $\mathrm{C}$ was a structured questionnaire to assess the prevalence of PMS among adolescent girls. The study variable was the prevalence of PMS among adolescent girls and the demographic variables were age, religion, residence, and socio-economic status. The clinical variables were height, weight, age at menarche, menstrual flow, and regular physical exercise.

\section{Criteria for sample selection}

The investigator approached the students based on the following selection criteria. The inclusion criteria were adolescent girls of 17-26 years of the age, who are willing to participate in this study and who know English and the exclusion criteria were students who are absent and students with gynecological problems such as amenorrhea, dysmenorrhea, menorrhagia, and metrorrhagia.

\section{Ethical consideration}

Formal approval was obtained from the Institutional Review Board and Institutional Ethical Committee of SRM University, Kattankulathur, Chennai, Tamil Nadu, India. In addition, the participants were informed of their right to withdraw anytime during the study.

\section{Instruments}

The tool was developed by the investigator himself the tool developed for this study is a self-administered questionnaire based on the review of literature discussion with experts and investigators personal experience. The tool comprises three sections. Section A includes demography variables which includes age, religion, residency, and socio-economic status. Section B includes clinical variables, which include height, weight, age at menarche, menstrual flow, and regular physical exercise. Section C which includes a structured questionnaire to assess the prevalence of PMS among adolescent girls. The scoring key interpretation includes 1-30\% comes under the category of the mild level PMS, moderate level PMS was between $34 \%$ and $66 \%$ and severe level PMS was between $67 \%$ and $100 \%$.

\section{Method of data collection}

The investigator has collected data with effect from February January 05 , 2015 to January 21, 2015 in SRM College of Nursing, Kattankulathur. The investigator introduced her samples, and the purpose of the study was explained to ensure better co-operation and collaboration during the data collection. The written consent from the samples was taken, and they were assured confidentiality.

Using questionnaire method, data collection procedure was completed. The structured questionnaire was administered to assess the prevalence of PMS among adolescent girls. Approximately 10-15 minutes was spent to elicit the data for each adolescent girl. The self-instructional module was distributed to each adolescent girl at the end of the data collection procedure. The data gathering process was continued till the sample size was 100 .

\section{Statistical analysis}

The information collected from the study participants was scored and tabulated. The data were entered into the master coding sheet and saved in Microsoft Excel. Statistical analysis was conducted using Statistical Package for Social Sciences-16. Mean, percentage, and standard deviation were used to explain the demographic variables, and Chisquare test was used to associate the demographic variables with PMS.

\section{RESULTS}

In the current study, 100 samples were assessed for the demographic variables, and it reveals that $51(51 \%)$ adolescents belong to the age group between 17 and 19 years; 46 (46\%) belongs to age group between 20 and 24 years; 3 (3\%) belongs to age groups between 24 and 26 years. Considering the religion 55 (55\%) belongs to Hindu; 35 (35\%) belongs to Christian; $10(10 \%)$ belongs to Muslim. Considering the place of residence $26(26 \%)$ stay in home; $69(69 \%)$ stay in hostel; and $5(5 \%)$ others. Considering the socio-economic status none of them in high class; $11(11 \%)$ are lower class; and 89 (89\%) are middle class. Considering the height $16(16 \%)$ are have below $150 \mathrm{~cm}$; 76 (76\%) are have $150-170 \mathrm{~cm}$; and $8(8 \%)$ are have above $170 \mathrm{~cm}$. Considering the weight $13(13 \%)$ are have below $40 \mathrm{~kg} ; 72(72 \%)$ are have 40-60 $\mathrm{kg} ; 15(15 \%)$ are have above $60 \mathrm{~kg}$. Considering the age of menarche $12(12 \%)$ are below 12 years; $75(75 \%)$ are between the age 12 and 14 years; and $13(13 \%)$ are between the age 14 and 18 years. Regarding their menstrual flow $76(76 \%)$ are have normal; $18(18 \%)$ are have scanty; 6 (6\%) are have heavy. Considering their daily exercise, 31 (31\%) are doing; 69 (69\%) are not doing (Table 1).

Table 1: Frequency and percentage distribution of demographic variables related to adolescents with PMS

\begin{tabular}{lll}
\hline Variable & Classification & n (\%) \\
\hline Age & $17-19$ & $51(51)$ \\
& $20-24$ & $46(46)$ \\
Religion & $24-26$ & $3(3)$ \\
& Hindu & $55(55)$ \\
Place of residence & Christian & $35(35)$ \\
& Muslim & $10(10)$ \\
Socio economic status & Home & $26(26)$ \\
& Hostel & $69(69)$ \\
Height (cm) & Others & $5(5)$ \\
& Lower & $11(11)$ \\
& Middle & $89(89)$ \\
Weight (kg) & $<150$ & $16(16)$ \\
& $150-170$ & $76(76)$ \\
Age at menarche (years) & $>170$ & $8(8)$ \\
& $<40$ & $13(13)$ \\
& $40-60$ & $72(72)$ \\
Menstrual flow & $>60$ & $15(15)$ \\
& $<12$ & $12(12)$ \\
& $12-14$ & $75(75)$ \\
Doing regular exercise & $14-18$ & $13(13)$ \\
& Normal & $76(76)$ \\
& Scanty & $18(18)$ \\
& Heavy & $6(6)$ \\
M=100. PMS: Premenstrual syndrom & Yes & $31(31)$ \\
& No & $69(69)$ \\
\hline
\end{tabular}

n=100. PMS: Premenstrual syndrome 
Table 2 shows that 26 (26\%) of adolescent girls have mild level of PMS; 55 (55\%) have moderate level of PMS; 19 (19\%) have a severe level of PMS.

All the values of $p>0.05$, and hence, we can conclude that there is no association between the "demographic variables" and the "levels of PMS (Table 3)."

\section{DISCUSSION}

PMS is psychosomatic disorder of unknown etiology often notice just before menstruation. The exact cause is unknown but progesterone, neuroendocrine factors play an important role, excess of prolactine, deficiency of vitamin B6 and magnesium, poor diet, depression, bipolar disorder, light sensitivity, pastsexual abuse, and un pleasant social situation. Diagnosis evaluation are history collection, physical examination [8].

Some of the common clinical features are physical symptoms include breast tenderness, blotting, water retention, acne, nipples discharges, fatigue, decreased sexual desire, headache. Behavioral symptoms include aggression, withdrawal from family and friends. Emotional and cognitive symptoms depression, sadness, hopelessness, anger, anxiety, irritability, mood swings, inability to concentration, decreased alertness, severe symptoms are having negative behavior, feel guild and shame, feel distance from family and friends [9].

Treatment of PMS include that cognitive behavioral therapy, exercises, drugs include such as tranquilizers, diuretics, antidepressant, modify

Table 2: Frequency and percentage distribution of prevalence of PMS

\begin{tabular}{lll}
\hline S. No. & Premenstrual syndrome & n (\%) \\
\hline 1 & Mild & $26(26)$ \\
2 & Moderate & $55(55)$ \\
3 & Severe & $19(19)$ \\
Total & & 100 \\
\hline
\end{tabular}

$\mathrm{n}=100$. PMS: Premenstrual syndrome died pattern, increased exercise, alleviate stress change activity of daily living will reduce fatigue and enhance ability to sleep. Surgical management of oophorectomy with gonadotropin-releasing hormone agonist therapy will treat PMS [3].

The aim of this study was to determine the prevalence of PMS among adolescent girls. The finding were $26(26 \%)$ of adolescent girls have mild level of PMS, 55 (55\%) have a moderate level of PMS, 19 (19\%) have a severe level of PMS. The current study was similar to the study of Yang in 2014 who had conducted a research study related to survey of premenstrual symptom severity and impairment in Korean adolescents: PMDD, subthreshold PMDD and PMS. In total, 20\% of adolescents reported suffering from distressing premenstrual symptoms, and girls with PMDD and subthreshold PMDD were very similar in their symptom severity and characteristics. Prospective daily charting is needed to confirm the accurate diagnosis and management of PMDD [10].

The second aim of this study was to associate the PMS with demographic variables. The finding related to this aim showed that statistically significant with the "Chi-square" all the value of $p>0.05$ and hence that there was no significant association between the demographic variables and level of PMS and it was associated with the following study findings. Wittchen et al. conducted a study to describe the prevalence, incidence, 12 comorbidity factors and correlates of threshold and subthreshold PMDD in a community sample of young women. Findings are based on prospective-longitudinal community survey of 1488 women aged 14-24, who were followed-up over 48 months (follow-up, $n=1251$ ) as part of the Early Developmental Stages of Psychopathology sample. Diagnostic assessments were based on the Composite International Diagnostic Interview and its 12-month PMDD diagnostic module administered by clinical interviewers. Diagnoses were calculated using DSM-IV algorithms, but daily ratings of symptoms, as required, were not available. The results were the baseline 12-month prevalence of DSM-IV PMDD was 58\%. The application of the diagnostic exclusion rules with regards to concurrent major depression and dysthymia decreased the rate only slightly (5.3\%). An additional $18.6 \%$ were "near-threshold" cases, mostly because they failed to meet the mandatory impairment criterion. Over the follow-up period, only a few new PMDD cases were

Table 3: Association between demographic variables and PMS

\begin{tabular}{|c|c|c|c|c|c|c|c|}
\hline \multirow[t]{2}{*}{ Variable } & \multirow[t]{2}{*}{ Classification } & \multicolumn{3}{|l|}{ PMS } & \multirow[t]{2}{*}{ Chi-square value } & \multirow[t]{2}{*}{ Degrees of freedom } & \multirow[t]{2}{*}{ p value } \\
\hline & & Mild & Moderate & Severe & & & \\
\hline \multirow[t]{3}{*}{ Age } & $17-19$ & 15 & 28 & 8 & 1.96 & 4 & 0.74 \\
\hline & $20-24$ & 11 & 25 & 10 & & & \\
\hline & $24-26$ & 0 & 2 & 1 & & & \\
\hline \multirow[t]{3}{*}{ Religion } & Hindu & 17 & 28 & 10 & 6.85 & 4 & 0.14 \\
\hline & Christian & 8 & 18 & 9 & & & \\
\hline & Muslim & 1 & 9 & 0 & & & \\
\hline \multirow[t]{3}{*}{ Place of residence } & Hostel & 21 & 33 & 15 & 4.97 & 4 & 0.29 \\
\hline & Home & 4 & 19 & 3 & & & \\
\hline & Others & 1 & 3 & 1 & & & \\
\hline \multirow[t]{2}{*}{ Socio economic status } & Lower & 2 & 7 & 2 & 0.46 & 2 & 0.79 \\
\hline & Middle & 24 & 48 & 17 & & & \\
\hline \multirow[t]{3}{*}{ Height } & $<150 \mathrm{~cm}$ & 5 & 9 & 2 & 1.36 & 4 & 0.85 \\
\hline & $150-170 \mathrm{~cm}$ & 20 & 41 & 15 & & & \\
\hline & $>170 \mathrm{~cm}$ & 1 & 5 & 2 & & & \\
\hline \multirow[t]{3}{*}{ Weight (kg) } & $<40$ & 3 & 7 & 3 & 2.87 & 4 & 0.58 \\
\hline & $40-60$ & 20 & 37 & 15 & & & \\
\hline & $>60$ & 3 & 11 & 1 & & & \\
\hline \multirow[t]{3}{*}{ Age at menarche (years) } & $<12$ & 2 & 8 & 2 & 1.05 & 4 & 0.90 \\
\hline & $12-14$ & 21 & 40 & 14 & & & \\
\hline & $14-18$ & 3 & 7 & 3 & & & \\
\hline \multirow[t]{3}{*}{ Menstrual flow } & Normal & 21 & 41 & 14 & 2.54 & 4 & 0.64 \\
\hline & Scanty & 5 & 10 & 3 & & & \\
\hline & Heavy & 0 & 4 & 2 & & & \\
\hline \multirow[t]{2}{*}{ Doing regular exercise } & Yes & 6 & 18 & 7 & 1.14 & 2 & 0.56 \\
\hline & No & 20 & 37 & 12 & & & \\
\hline
\end{tabular}

n=100. PMS: Premenstrual syndrome 
observed: Cumulative lifetime incidence was 7.4\%. PMDD syndrome was stable across 48 months with $<10 \%$ complete remissions among baseline PMDD cases. The 12-month and lifetime comorbidity rates were high (anxiety disorders 47.4\%, mood disorders 22.9\%; somatoform $28.4 \%$ ), only $26.5 \%$ had no other mental disorder. Particularly, high odds ratios were found with nicotine dependence and PTSD. In terms of correlates increased rates of 4-weeks impairment days, high use of general health and mental health services, and increased rates of suicide attempts were found. They concluded sample of adolescents and young adults, premenstrual symptoms were widespread. However, DSMIV PMDD was considerably less prevalent. PMDD is a relatively stable and impairing condition, with high rates of health service utilization, increased suicidality, and substantial co-morbidity.

PMS or premenstrual syndrome is a condition that manifests as emotional, physical, and behavioral symptoms and affects women between their late 20 seconds and early 40 seconds. For all the sociodemographic factors and related factors that were studied, it emerged from the findings of the study. That continuous follow-up in the hospital, previous history of depression and low income were statistically associated with scoring positive to PMS [11].

\section{CONCLUSION}

The study concludes among 100 chosen samples regarding the prevalence of PMS among adolescent girls at SRM College of Nursing, SRM University, Kattankulathur. Among the students, $26 \%$ have a mild level of PMS, 55\% have a moderate level of PMS, and 19\% have a severe level of PMS. The "Chi-square test" revealed that there is no significant association between the demographic variables and level PMS.

\section{ACKNOWLEDGMENT}

The author acknowledges Dr. Jaya Mohan Raj, Former Dean, SRM College of Nursing for constant guidance. We would like to thank study participants and Mr. Karnamurthy $\mathrm{P}$ and friends for their constant support.

\section{REFERENCES}

1. Edmonds K. Dewhurst's Text Book of Obstetrics and Gynaecology for Postgraduates. $6^{\text {th }}$ ed. United State: Oxford University; 1999. p. 41, 43.

2. American College of Obstetricians and Gynecologists. Premenstrual Syndrome Management Guidelines for Obstetrics-Gynecologists. ACOG Practice Bulletin. Vol. 15. Washington, DC: American College of Obstetricians and Gynecologists; 2000. p. 1-9.

3. Rayburn WF. Text Book of Obstetrical and Gynaecology. $3^{\text {rd }}$ ed. Philadelphia, PA: BI Iravely Publication; 1996. p. 311-5.

4. Bakhshani NM, Hosseinbor M, Shahraki Z, Sakhavar N. Premenstrual syndrome symptomatology among married women of fertile age based on methods of contraception (hormonal versus non-hormonal methods of contraception). Glob J Health Sci 2014;6(2):105-11.

5. Al-Batanony MA, El-Shafie MK. Work-related health effects among wastewater treatment plants workers. Int J Occup Environ Med 2011;2(4):237-44.

6. Kaur N, Thakur R. A study to assess the premenstrual syndrome and coping behaviour among nursing students, nine PGIMER, Chandigarh. Nurs Midwifery Res J 2009;5(1):1-5.

7. Rapkin A. A review of treatment of premenstrual syndrome \& premenstrual dysphoric disorder. Psychoneuroendocrinology 2003;28(3):39-53

8. Walsh MJ. Text book Office Gynaecology. $4^{\text {th }}$ ed. Baltimore: Williams \& Willkins; 2006. p. 253, 259

9. Richarson JT. Text book of Gynaecology. $12^{\text {th }}$ ed. New Delhi: BT Churchill Livingstone; 1999. p. 226.

10. Yang J, Joe SH, Lee MS, Kim SH, Jung IK. Survey of premenstrual symptom severity and impairment in Korean adolescents: Premenstrual dysphoric disorder, subthreshold premenstrual dysphoric disorder and premenstrual syndrome. Asia Pac Psychiatry 2014;6(2):135-44.

11. Wittchen HU, Becker E, Lieb R, Krause P. Prevalence, incidence and stability of premenstrual dysphoric disorder in the community. Psychol Med 2002;32(1);119-32. 